\title{
Medical Spending in the US: Facts from the Medical Expenditure Panel Survey Dataset
}

\author{
Svetlana Pashchenko* \\ University of Surrey
}

\author{
Ponpoje Porapakkarm ${ }^{\dagger}$ \\ National Graduate Institute \\ for Policy Studies
}

July 16, 2015

\begin{abstract}
We document facts about medical spending of the US population using the Medical Expenditure Panel Survey dataset. We find that for the entire population, around $44 \%$ of the total medical spending is paid by private insurance but there is a substantial difference in terms of financing medical care by age: for working age adults ( 25 to 65 years old) private insurance covers around $57 \%$ of the total medical spending, whereas for the elderly (older than 65 years old) the largest payor is the government which covers $65 \%$ of the total. Inpatient hospital care accounts for a third of the aggregate medical expenditures. Medical spending is highly concentrated: the top $5 \%$ of spenders account for more than half of the total expenditure. Even higher concentration is observed among hospital spending where the top $5 \%$ of spenders contribute around $80 \%$ to the total expenditure. The concentration in medical spending decreases with age: the Gini coefficient of the total medical spending is 0.75 for people aged between 25 and 64 years old and 0.63 for people older than 65 years old. We find that average medical spending of people in the bottom income quintile is higher than that of people in the top income quintile for all age groups. In terms of persistence of medical spending, we find that the correlation of medical expenditure in two consecutive years is 0.36 . When persistence is measured by quintile of medical spending distribution, medical spending of people in the bottom and top quintiles has higher persistence relative to other groups.
\end{abstract}

Keywords: medical spending, health insurance, health care

JEL Classification Codes: D12, D14, I13, I14

\footnotetext{
*Email: sap9v@virginia.edu

†Email: p-porapakkarm@grips.ac.jp
} 


\section{Introduction}

In this article we document facts about medical spending of the US population. The US represent an interesting case study because unlike other developed countries it does not have universal public health insurance. Individuals in the US obtain health insurance from different sources and in most cases the source of insurance coverage changes over the life-cycle. People over 65 are eligible for public health insurance, while the majority of the non-elderly population are covered by private insurance. Certain groups of young adults are uninsured or are covered by means-tested public health insurance. As a result, there exists inequality in terms of access to health care, and an important question is how this may affect medical spending over the life-cycle, as well as concentration of medical spending and its correlation with income.

For our analysis we use the Medical Expenditure Panel Survey dataset. This dataset contains very detailed information about medical spending at the individual level. It covers individuals of all ages but age is top-coded at 85. An important feature of MEPS is that medical spending information is collected at the event level (e.g. visit to a specialist, hospital stay), thus all spending can be linked to a particular health service. Individuals' responses are cross-checked with medical providers and insurance companies, which improves the accuracy of the data. However, since this dataset only includes noninstitutionalized population and excludes hospital stays over 45 days it misses information on catastrophic medical spending.

The paper is organized as follows. Section 2 reviews the related literature. Section 3 provides a brief review of the US health insurance system. Section 4 describes the MEPS dataset and compares certain aggregate statistics constructed from MEPS with other datasets. Section 5 documents facts related to the distribution of medical spending and its correlation over time. Section 6 describes the evolution of medical spending over the life-cycle. Section 7 concludes.

\section{Related literature}

This paper relates to the literature documenting micro-level facts about individual medical spending over the life-cycle in the US. The studies in this area differ in terms of the dataset they use and the subset of the population they consider. In particular, Crystal et al (2000) and De Nardi et al. (2015) use the Medicare Current Beneficiary Survey (MCBS), whereas Fahle et al. (2015), Goldman and Zissimoulos (2003) and Hurd and Rohwedder (2009) use the Health and Retirement Survey dataset (HRS) which includes individuals over the age of 50. Since both the MCBS and HRS datasets do not include young individuals, all the aforementioned studies focus on the elderly population. Evans and Humphreys (2015) and Calonico et al. (2015) use the claims data from private 
insurers and focus on non-elderly individuals.

In contrast to the studies above, studies that use MEPS can analyze medical spending of both the elderly and non-elderly population, with the exception of those over 85 years old. To the best of our knowledge, only the study by Jung and Tran (2013) uses MEPS to document individual level facts about medical spending. Specifically, they focus on estimating age profiles of average medical spending controlling for both time and cohort effects. There are also several studies that compare MEPS with other datasets. Bernard et al. (2012), Sing et al. (2006), and Selden et al. (2001) compare the aggregate medical expenditure estimates using the MEPS and National Health Expenditure Accounts (NHEA). Aizcorbe et al. (2012) compare the medical spending of people with employer-based health insurance in MEPS and the MarketScan data. Yabroff et al (2009) compare medical costs among individuals with certain cancer diagnosis using the MEPS and Medicare claims data.

\section{Institutional framework}

One important feature of the US health care system is the absence of universal public health insurance. Public health insurance still plays an important role in the US health insurance system but it covers only certain groups of population. Two largest public health insurance programs are Medicare and Medicaid. Medicare covers people older than 65 years old as well as disabled young people. Medicaid is a means-tested program that covers individuals of all ages whose resources fall below a certain threshold. For many low-income young adults Medicaid is the main source of insurance coverage. For people older than 65 years old Medicaid serves as supplemental health insurance that covers certain categories of medical spending not covered by Medicare, most importantly nursing home stays. Apart from Medicaid and Medicare there exist several other smaller public insurance programs targeted at specific groups of people, for example State Children's Health Insurance Program (SCHIP), Tricare (for military personnel), and Veteran's Health Administration. Because public health insurance covers people that on average have high medical spending (the elderly and the disabled), the government contributes a substantial share of the national health expenditure (see Section 5.1).

For non-elderly adults in the US there exists substantial heterogeneity in terms of sources of insurance coverage (Table 1). ${ }^{1}$ The majority of non-elderly adults $(68 \%)$ are covered by private insurance, mostly obtained through employers (59\%). Employer-based health insurance (ESHI) is tightly regulated: employers cannot differentiate premiums based on age or health conditions of individuals. Thus all employees of the same company

\footnotetext{
${ }^{1}$ In Table 1 individuals with both public and private insurance are added to both categories, so the distribution by coverage does not sum up to $100 \%$.
} 
are charged the same premium as long as they buy the same plan (87\% of US firms that offer health benefits to their workers only provide one plan choice, Kaiser Family Foundation, 2013). This is one of the reasons why large firms are more likely to offer ESHI to their employees because in small firms one employee with poor health conditions can increase the premiums for the entire pool of workers. In 2013, 99\% of all large firms (with 200 or more workers) offered health benefits to their workers, while among small firms (3-199 workers) only 57\% did so (Kaiser Family Foundation, 2013).

\begin{tabular}{lc}
\hline Type of insurance & Coverage (\%) \\
\hline Uninsured & 18.4 \\
Public insurance & 18.2 \\
Private insurance & 68.1 \\
$\quad$ Employer-based & 59.2 \\
Directly-purchased & 9.1 \\
\hline
\end{tabular}

Table 1: Distribution of people aged 18-64 years old by insurance status in 2013. Source: US Census

Outside the employer-based market the private health insurance market is rather small: only $9 \%$ of non-elderly adults purchase their health insurance directly in the individual market. One important difference between directly-purchased insurance and ESHI is that until recently insurers could risk-adjust prices in the individual market in most states, i.e. sick individuals were charged higher premiums. Moreover, individuals with chronic health conditions could be denied coverage or only offered plans that do not cover preexisting conditions. The situation in the individual market has changed substantially since 2014 when the Patient Protection and Affordable Care Act (ACA), which introduces a number of new regulations in the health system, become effective. In particular, insurance companies are not allowed to adjust premiums based on health conditions of individuals (even though premiums can vary by age) or deny/limit coverage based on preexisting conditions.

Another important characteristics of the US health insurance system is that coverage varies significantly by income level (Table 2). More specifically, among low-income individuals (income less than $\$ 25,000$ ), $21.6 \%$ are uninsured and only $26.7 \%$ are covered by ESHI, while among high-income individuals (income in the range $\$ 100,000-\$ 150,000$ ) only $6.3 \%$ are uninsured and $86.1 \%$ are covered by ESHI. In Section 5 we will discuss how this phenomenon can possibly affect the income-medical spending gradient. 


\begin{tabular}{lcccccc}
\hline Type of insurance & \multicolumn{6}{c}{ By household income $(\$ 000)$} \\
\cline { 2 - 7 } & $<25$ & $25-50$ & $50-75$ & $75-100$ & $100-150$ & $150>$ \\
\hline Uninsured & 21.6 & 18.7 & 13.1 & 9.7 & 6.3 & 5.3 \\
Public insurance & 62.5 & 45.9 & 30.8 & 21.5 & 17.3 & 14.1 \\
Private insurance & 26.7 & 50.3 & 69.7 & 79.6 & 86.1 & 89.8 \\
\hline
\end{tabular}

Table 2: Distribution of people by insurance and income in 2013. Source: US Census

\section{The MEPS dataset}

\subsection{Description}

For our analysis, we use data from the 1999-2012 waves of the Medical Expenditure Panel Survey (MEPS), a nationally representative survey of the civilian noninstitutionalized population produced by the Agency for Health Care Research and Quality (AHRQ). It includes data on health care use, expenditures, sources of payment, health insurance coverage, health status, demographic and socio-economic characteristics. The survey is designed as a two-year rotating panel. It includes five rounds of interviews covering two full calendar years. Each annual sample size is about 15,000 households. The set of households selected for each panel of MEPS is a subsample of households participating in the previous year's National Health Interview Survey (NHIS) conducted by the National Center for Health Statistics. While this survey oversamples blacks and hispanics, MEPS further oversamples additional policy relevant subgroups such as lowincome households. MEPS adjusts (post-stratifies) person weights so that it produces the same poverty rates by demographic groups as the Current Population Survey (CPS), a dataset used as the source of official poverty statistics in the US (Banthin and Selden, 2006).

MEPS consists of three components: household, medical provider and insurance. The Household Component (HC) data is based on a survey of individuals and it is publicly available. The Medical Provider Component (MPC) is a follow-back survey of medical providers reported by $\mathrm{HC}$ respondents and also providers who provide services for patients in hospitals but bill separately from hospitals. MPC data is used to crosscheck information collected from the household survey to improve the accuracy of the expenditure data. The Insurance Component (IC) comes from a survey of employers and collects information on health insurance plans offered. Both MPC and IC data are not publicly available. ${ }^{2}$ Since in our analysis we use HC, in the following we refer to MEPS $\mathrm{HC}$ as MEPS.

In our sample we dropped individuals with missing values of age or medical spending. This leaves us with 257,222 individuals who contribute to 463,495 person-year observa-

\footnotetext{
${ }^{2} \mathrm{IC}$ data is available on the AHRQ website in tabular form only.
} 
tions. For our longitudinal analysis in Section 5.3, we keep only individuals whom we observe for two years, and this reduces our sample size to 198,517 individuals. We use the cross-sectional weights and longitudinal weights provided by MEPS for the crosssectional and longitudinal pools correspondingly. Since each wave is a representation of the population in that year, when pooling several years (or waves) together the weight of each individual was divided by the number of years (or waves). We use 2014 as the base year. All level variables were normalized to the base year using the Consumer Price Index (CPI).

The MEPS data is collected at the event level and then it is summed up to produce annual utilization and expenditure. MEPS includes the following categories of medical expenses: office-based visits (medical provider visits that took place in office-based settings and clinics), hospital events (inpatient and outpatient care, emergency room visits), dental care, vision aids, home health care, other medical equipment and services, and prescribed medicine. It should be noted that MEPS does not include information on events such as nursing home care and hospital stays longer than 45 days. This, coupled with the fact that age in MEPS is top-coded at 85 years, does not allow to use the dataset to analyze the medical spending of the very elderly and medical spending before death.

MEPS defines medical expenditure as the the sum of direct payments for health care services made by insurers or out-of-pocket. Payments that cannot be linked to a particular patient are not included in MEPS definition of expenditure (e.g. Medicaid Disproportionate Share Hospital payments). Similarly, uncollected liability and bad debt are not counted as expenditures because no payment is maid. Moreover, MEPS adjusts household-reported insurance payments because households may not know that their insurer negotiated a discount with the provider. In addition, medical expenditure in MEPS do not include over-the-counter drugs. MEPS also report charges variables with the caution that they do not represent the actual amount paid for the services. The difference between charges and actual payments can be substantial. In our sample, the average charges for all services excluding prescription drugs is $\$ 6,609$ while the average expenditures is only $\$ 3,092 .{ }^{3}$ This large discrepancy suggests that negotiated discounts, bad debt, and free care are substantial.

MEPS collects income and medical spending information at the individual level. The income sources in MEPS include wage and salary income, business and sales income, interest and dividend income, pension and Social Security income, as well as income from public assistance, Supplemental Security Income (SSI), child support, Temporary Assistance for Needy Families (TANF), and unemployment compensation. All personlevel income amounts (both total and separate sources of income) are top-coded at 99th percentile.

\footnotetext{
${ }^{3}$ The median charges for our sample is $\$ 802$ and median expenditures is $\$ 541$.
} 


\subsection{Comparison to other datasets}

MEPS is not designed to yield the aggregate national estimates of medical expenditure. In fact, the discrepancy between MEPS and the aggregate statistics is substantial. Table 3 shows the ratio of the aggregate medical spending computed from the National Health Expenditure Account (NHEA) to the aggregate spending computed from the MEPS., ${ }^{4,5}$ Overall, the national average is at least $65 \%$ higher than the corresponding statistics in MEPS. Two important sources of this discrepancy is the absence of certain categories of medical care from MEPS (e.g. nursing home care) and the different approach to define medical spending. As mentioned above, medical spending in MEPS is based on the actual payments made for a particular service. In contrast, NHEA estimates are based on providers' revenue even if it is not associated with a particular event (e.g. revenue from hospital gift shops or parking lots).

\begin{tabular}{cccc}
\hline Year & MEPS & NHEA & NHEA/MEPS \\
\hline 2000 & 627.9 & $1,165.7$ & 1.86 \\
2001 & 726.4 & $1,265.8$ & 1.74 \\
2002 & 810.7 & $1,371.9$ & 1.69 \\
2003 & 895.5 & $1,482.1$ & 1.66 \\
2004 & 963.9 & $1,592.3$ & 1.65 \\
2005 & $1,023.8$ & $1,700.9$ & 1.66 \\
2006 & $1,033.1$ & $1,809.3$ & 1.75 \\
2007 & $1,126.1$ & $1,921.0$ & 1.71 \\
2008 & $1,148.4$ & $2,017.3$ & 1.76 \\
2009 & $1,259.5$ & $2,117.9$ & 1.68 \\
2010 & $1,263.4$ & $2,196.2$ & 1.74 \\
2011 & $1,330.7$ & $2,281.8$ & 1.71 \\
2012 & $1,350.7$ & $2,379.3$ & 1.76 \\
\hline
\end{tabular}

Table 3: Medical expenses in the MEPS and NHEA (billions, current dollars) and their ratio

Bernard et al. (2012) and Sing et al. (2006) provide a detailed study of the discrepancy between the NHEA and MEPS estimates. The first study compares the MEPS and NHEA estimates for 2007, and the second compares those for 2002. The authors construct an adjusted NHEA estimate of the aggregate medical spending that excludes nursing home costs, acute health expenditures of people who spend more than 45 days in a hospital, expenditure for active military personnel and foreign visitors, and several other categories of medical expenditure not included in MEPS. The resulting estimate of the aggregate medical spending from NHEA is much closer to its counterpart in MEPS: the difference is reduced to $14 \%$ in 2002 and to around $18 \%$ in 2007 . The authors attribute

\footnotetext{
${ }^{4}$ The NHEA is based on the aggregate provider revenue data.

${ }^{5}$ When computing the aggregate medical expenses in Table 3 we include all observations even those with missing data on age.
} 
the remaining difference to factors such as the presence of undetected fraudulent billing practices in NHEA, underreporting of prescription drug spending in MEPS, and the underrepresentation of people with more than $\$ 100,000$ in total annual health expenditures in MEPS.

To understand how accurately MEPS captures information on the elderly, in Table 4 we compare the average medical spending per Medicare beneficiary and Medicare enrollment for people older than 65 years old in MEPS and the Medicare Current Beneficiary Survey (MCBS). ${ }^{6}$ Numbers from MCBS in the table are from De Nardi et al. (2015). MEPS underestimates Medicare enrollment comparing to MCBS, especially in years 1999 and 2000, but after 2001 the gap between the two datasets is around one million individuals. The difference in average medical spending per beneficiary is more substantial: the MEPS estimates are lower and the gap between the two datasets varies between $34 \%$ and $64 \%$. This difference is driven by the same factors that account for the difference between MEPS and NHEA described earlier: the absence of information on nursing home care episodes and underrepresentation of high cost cases.

\begin{tabular}{cccccc}
\hline Year & \multicolumn{2}{c}{$\begin{array}{c}\text { Enrollment } \\
\text { (millions) }\end{array}$} & \multicolumn{2}{c}{ Mean } & Expenditure \\
& MEPS & MCBS & MEBS /MEPS & MCBS & \\
\hline 1999 & 32.4 & 35.0 & 4,166 & 6,450 & 1.55 \\
2000 & 32.9 & 35.1 & 4,065 & 6,650 & 1.64 \\
2001 & 34.2 & 35.5 & 4,442 & 7,030 & 1.58 \\
2002 & 34.3 & 35.9 & 5,076 & 7,490 & 1.48 \\
2003 & 34.9 & 36.2 & 5,272 & 7,510 & 1.42 \\
2004 & 35.5 & 36.3 & 5,547 & 7,690 & 1.39 \\
2005 & 35.6 & 36.6 & 5,260 & 7,880 & 1.50 \\
2006 & 35.9 & 36.9 & 5,972 & 8,640 & 1.45 \\
2007 & 36.7 & 37.8 & 6,696 & 8,990 & 1.34 \\
2008 & 37.7 & 38.7 & 5,926 & 9,110 & 1.54 \\
2009 & 38.4 & 39.6 & 6,247 & 9,210 & 1.47 \\
2010 & 39.2 & 40.6 & 6,632 & 9,340 & 1.41 \\
\hline
\end{tabular}

Notes: Adjusted to 2014 dollars

Table 4: Medicare enrollment and expenditures for the age 65+ population, MEPS and MCBS

To understand how accurate the information on insurance coverage for non-elderly adults in MEPS is, we compare it with the aggregate data from CPS. The CPS Annual Social and Economic Supplement (ASEC) is the most widely-cited source of estimates on health insurance and the uninsured (Smith and Medalia, 2013). ASEC is conducted in February, March and April and respondents are asked about their health insurance

\footnotetext{
${ }^{6} \mathrm{MCBS}$ is a nationally representative survey of Medicare beneficiaries. More details on this dataset are available in De Nardi et al. (2015).
} 
coverage in the previous calendar year. Individuals are considered to be insured if they were covered by some health insurance for part or all of the year, and they are considered uninsured if they did not have any coverage for the entire year. Individuals who report multiple sources of coverage are included in several categories (e.g. public and private insurance). We construct the insurance statistics from MEPS to be as close to the CPS definition as possible. MEPS asks individuals retrospectively about the source of their coverage for each month of the year. We define an individual as insured if he reports having coverage for at least one month of the year. An individual is classified as uninsured if he reports having no coverage for all twelve months of the year. To be consistent with the CPS definition, we add individuals who report having both public and private insurance to both categories (because of this the distribution of individuals by insurance does not sum up to $100 \%$ ). Table 5 compares the resulting insurance statistics for people aged 18 to 64 years old between MEPS and CPS in 2012. Overall, the insurance coverage in MEPS is close to its counterpart in CPS. The percentage of the uninsured is higher in CPS, however until recently CPS produced higher estimates of the uninsured than other federal studies (Smith and Medalia, 2013). Czajka and Denmead (2008) compare eight datasets including MEPS and CPS and also find that CPS overestimates the number of uninsured comparing to all other datasets. They conjecture that this happens because respondents in CPS answer the question whether they were uninsured for the entire prior year or not based on the current insurance situation. ${ }^{7}$

\begin{tabular}{lcc}
\hline Type of insurance & MEPS & CPS \\
\hline Uninsured & 18.4 & 21.0 \\
Public insurance & 16.4 & 16.6 \\
Employer-based insurance & 68.7 & 67.2 \\
\hline
\end{tabular}

Table 5: Distribution of people age 18-64 years old by insurance status in 2012 in MEPS and CPS

Table 6 compares median household income in MEPS and CPS. To construct household income in MEPS we use the variable "total person-level income" (TTLP) that was designed to match as closely as possible the CPS definition of income. Since MEPS provides all the information at the individual level we link individuals to a family and then sum income of all family members. MEPS allows to link individuals into family using several definitions of a family. The first definition of family is based on the eligibility for a family insurance plan. The group of individuals linked this way are referred to as the Health Insurance Eligibility Unit (HIEU). The second way to link individuals is based on the CPS definition of a family. The third way is the MEPS definition of a family which differs from the CPS definition in terms of how it treats foster children and cohabitants.

\footnotetext{
${ }^{7}$ To address this problem CPS redesigned insurance questions in 2013. More details on this are provided in Smith and Medalia (2013).
} 
To construct household income we use the CPS definition of a family and compute the mean and median using the family weights provided in MEPS. The average income in both datasets are almost identical, but the median income is almost $9 \%$ higher in MEPS. Czajka and Denmead (2008) provide a more detailed comparison between the MEPS and CPS income distributions and find that MEPS has higher income than CPS between the 20th and 80th percentiles. For the bottom and the top income quintiles, however, MEPS underestimates income comparing to CPS. Czajka and Denmead (2008) caution that this comparison may be not very informative because MEPS post-stratifies the data to CPS poverty distribution, thus it is not clear if the discrepancy in income data is due to the way data is collected or to the post-stratification.

\begin{tabular}{lccc}
\hline & MEPS & CPS & CPS/MEPS \\
\hline Average & 70,959 & 71,274 & 1.00 \\
Median & 55,691 & 51,017 & 0.92 \\
\hline
\end{tabular}

Table 6: Average and median household income in 2012 in MEPS and CPS

\section{Medical Expenditures in the Cross-Section and Over Time}

\subsection{The Cross-Sectional Distributions}

Table 7 displays the distribution of medical spending by payors and by type of care. Payors include out-of-pocket spending, private insurance and the government (Medicaid, Medicare and other public insurance). The sum of contributions by payor does not sum up to $100 \%$ because we do not report contributions from Tricare, worker compensation and unclassified sources. For spending by Tricare, this variable is only available since 2000. We do not report spending covered by worker compensation and spending by unclassified sources because it is not clear which type of payors they belong to. The reported in Table 7 expenditure categories are hospital costs (split into inpatient and outpatient), office-based visits, prescription drugs and other costs, which is the sum of dental care, home health care, vision aids and medical supplies and equipment. For all numbers in Table 7 we first calculate the means of each category of medical spending and the mean of total spending, and then take their ratio. Table A1 in the Appendix reports the same statistics but when we first calculate the ratio of each category of spending to the total and then compute the average.

For the entire sample, the largest share of the total medical spending is paid by private insurance (43.8\%), followed by the government as the second largest payor (35.4\%). This 
distribution, however, significantly changes with age: for people between 25 and 64 years old private insurance covers $57.1 \%$ of total spending and the government covers $20.4 \%$, while for people older than 65 years old the share of private insurance decreases to $17 \%$ and the share of the government increases to $65.4 \%$. This happens because of the change in the source of insurance coverage for most people after age 65 from private to public as discussed in Section 3. Comparing to men, women have higher percentage of their medical costs covered out-of-pocket ( $18.5 \%$ for women vs $16.3 \%$ for men) and by Medicaid (11\% vs $8.7 \%)$ and this difference is particularly marked amongst people older than 65 years old.

In terms of the type of expenditure, the largest category is hospital costs that constitute $42.5 \%$ of the total spending, most of which is inpatient care (33.3\%). Office-based visits and prescription drugs each accounts for around $20 \%$ of the total spending. Women spend considerably more on office-based visits between ages 25 and 65 (26.1\% for women vs $21.7 \%$ for men), while men spend more on hospital care, especially when they are older than 65 (41.9\% for women vs $47.2 \%$ for men).

In Table 8 we report the distribution of total and hospital medical spending, as well as the distribution of spending for two most important payor types: out-of-pocket and private insurance for people younger than 65 years old, and out-of-pocket and Medicare for people older than 65 years old. People in the top $5 \%$ of the medical expenditure distribution spend on average around $\$ 35,000$, which is almost nine times higher than the average for the whole sample $(\$ 3,905)$. The average spending of the top $5 \%$ considerably increases with age: after age 65 the average spending of the top $5 \%$ constitutes more than $\$ 65,000$. It should be noted that people in the top $5 \%$ account for more than half $(52 \%)$ of the total medical spending. This inequality decreases with age: for people in the age range 25 to 64 years old, the top $5 \%$ of spenders account for $49 \%$ of total spending, while for people older than 65 years old this number decreases to around $34 \%$. Inequality in hospital care spending is even higher: $70 \%$ of population spend almost nothing on hospital care, while those in the top $5 \%$ of the distribution on average spend around $\$ 24,000$. The usage of hospital care increases with age, but even for people after age 65 , $50 \%$ have almost zero hospital spending.

The bottom panel of Table 8 shows that on average people pay $\$ 685$ out-of-pocket, however the top $5 \%$ of spenders pay on average $\$ 5,154$. As in the case of total spending, out-of-pocket spending increases substantially with age: people older than 65 years old pay on average $\$ 1,534$, while the top $5 \%$ of spenders pay $\$ 9,006$ on average. It should be noted that the spending contributed by private insurance is more concentrated than the total or out-of-pocket medical spending: the top $5 \%$ of spenders account for more than $66 \%$ of the total spending by private insurance, while these numbers are $52.0 \%$ and $46.7 \%$ for total and out-of-pocket spending correspondingly. 


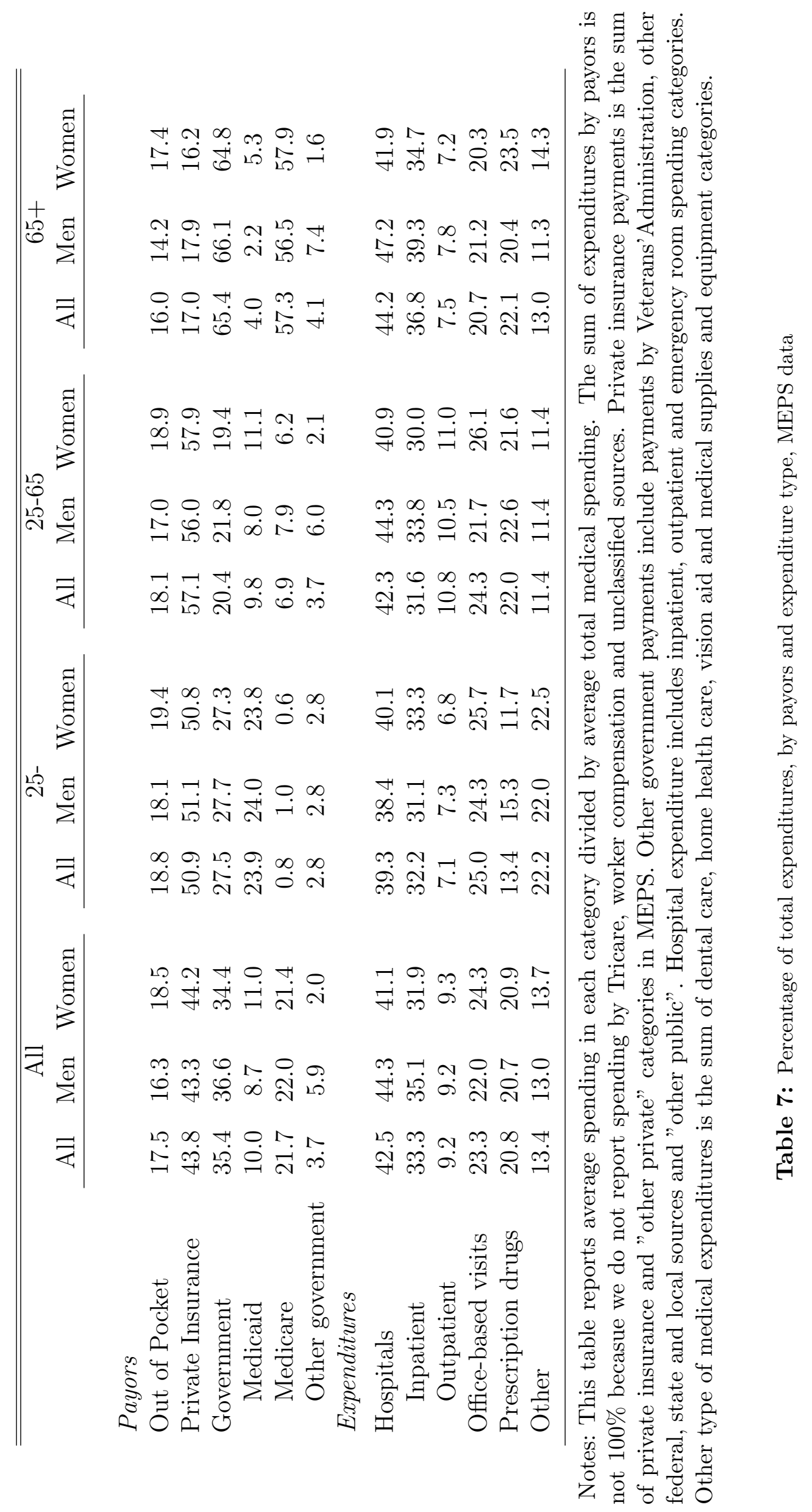




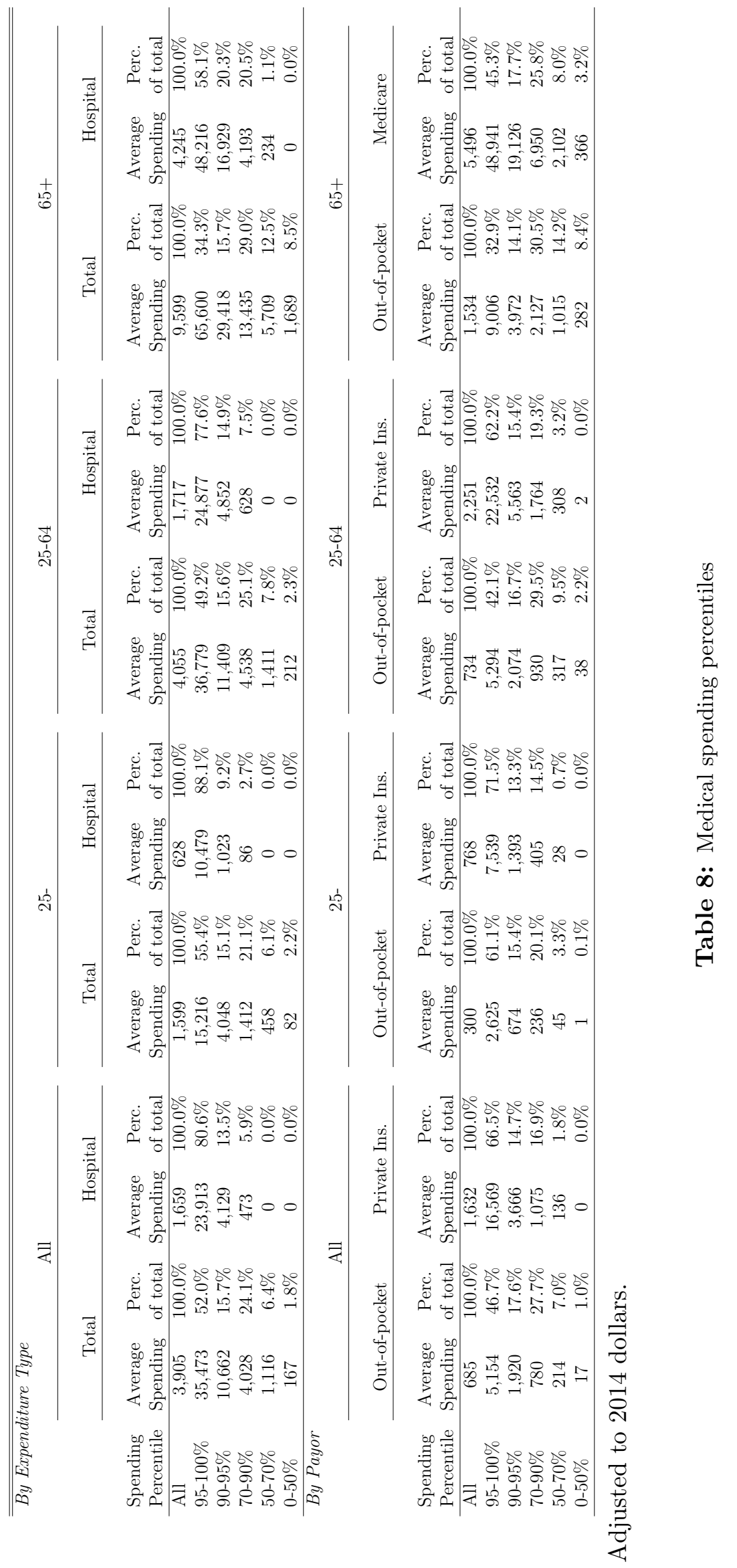


Table 9 shows the quintiles of total and hospital medical spending for men and women, and for different age groups. On average, women spend more then men $(\$ 4,334$ vs $\$ 3,456)$, but this difference disappears with age: for people older than 65 years old average spending of men $(\$ 9,748)$ is almost the same as that of women $(\$ 9,486)$. A similar trend is observed in hospital spending: women spend more than men when young but for older group men's spending becomes higher than that of women.

\begin{tabular}{|c|c|c|c|c|c|c|}
\hline \multicolumn{7}{|l|}{$\overline{\text { All }}$} \\
\hline & \multicolumn{3}{|c|}{ Total Expenditure } & \multicolumn{3}{|c|}{ Hospitals } \\
\hline & All & Men & Women & All & Men & Women \\
\hline All & 3,905 & 3,456 & 4,334 & 1,659 & 1,530 & 1,783 \\
\hline Bottom & 0 & 0 & 12 & 0 & 0 & 0 \\
\hline Fourth & 156 & 83 & 248 & 0 & 0 & 0 \\
\hline Third & 618 & 422 & 856 & 0 & 0 & 0 \\
\hline Second & 2,048 & 1,478 & 2,648 & 28 & 1 & 86 \\
\hline Top & 14,161 & 12,785 & 15,215 & 7,575 & 7,028 & 8,126 \\
\hline \multicolumn{7}{|c|}{ Ages 25-64 } \\
\hline & \multicolumn{3}{|c|}{ Total Expenditure } & \multicolumn{3}{|c|}{ Hospitals } \\
\hline & All & Men & Women & All & Men & Women \\
\hline All & 4,055 & 3,470 & 4,616 & 1,717 & 1,537 & 1,889 \\
\hline Bottom & 0 & 0 & 18 & 0 & 0 & 0 \\
\hline Fourth & 182 & 63 & 366 & 0 & 0 & 0 \\
\hline Third & 806 & 457 & 1,195 & 0 & 0 & 0 \\
\hline Second & 2,445 & 1,647 & 3,234 & 44 & 0 & 159 \\
\hline Top & 14,888 & 13,220 & 16,026 & 8,045 & 7,147 & 8,751 \\
\hline \multicolumn{7}{|c|}{ Ages $65+$} \\
\hline & \multicolumn{3}{|c|}{ Total Expenditure } & \multicolumn{3}{|c|}{ Hospitals } \\
\hline & All & Men & Women & All & Men & Women \\
\hline All & 9,599 & 9,748 & 9,486 & 4,245 & 4,597 & 3,979 \\
\hline Bottom & 439 & 354 & 516 & 0 & 0 & 0 \\
\hline Fourth & 1,904 & 1,717 & 2,046 & 0 & 0 & 0 \\
\hline Third & 4,041 & 3,783 & 4,223 & 23 & 5 & 40 \\
\hline Second & 8,321 & 8,030 & 8,527 & 1,057 & 1,031 & 1,071 \\
\hline Top & 31,992 & 33,131 & 31,090 & 19,625 & 21,324 & 18,338 \\
\hline
\end{tabular}

Adjusted to 2014 dollars.

Table 9: Mean total and hospital expenditures sorted by expenditure quintile and gender 


\subsection{The Distribution by Income}

To understand how different are medical spending of people in different income group, we report the mean income and medical spending (both total and hospital) for each income quintile in Table 10. For this analysis we exclude people younger than 25 years old since in MEPS income is reported at individual level and many of the very young individuals do not have own income and receive family transfers. One key observation from Table 10 is that the level of the average medical spending does not increase with income quintile. In fact, people in the bottom income quintile spend more than people in the top quintile: spending of the former group is $\$ 6,052$ while spending of the latter is $\$ 4,333$. This applies to both men and women, people older and younger than 65 years old, and total and hospital spending. To illustrate this issue further, Table 11 displays the ratio of the average medical spending of people in the top income quintile to those in the bottom quintile. This ratio is always less than one, and the largest difference in spending between the top and bottom income quintiles is observed for hospital care for men younger than 65 years old (0.41). It should also be noted that for men, the gap between the top and bottom income quintiles in terms of the average medical spending decreases with age.

Table 12 displays the distribution of medical spending by income for different payors and different categories of expenditure, and Table 13 provides the same statistics separately for people younger and older than 65 years old. As for Table 10, we exclude people younger than 25 years old from this analysis. For the entire sample, out-of-pocket medical spending does not vary significantly by income quintile. However, for people older than 65 years old there exists a monotone relationship between income and out-of-pocket spending: people in the bottom quintile spend $\$ 1,237$ out-of-pocket, while this number for people in the top quintile is $\$ 1,715$. It should be noted that this is quite different from the relationship between income and total medical spending described earlier where the low-income group spend more than the high-income group. Another observation from Tables 12 and 13 is that payments by private insurance are highest for the top income quintiles, while payments by Medicaid are highest for the bottom quintiles. This can be explained by the correlation between income and insurance status described earlier: Medicaid is a means-tested program, while private health insurance is mostly available to high-income people. Unlike Medicaid, another public insurance program, Medicare, is an important source of financing medical spending for people older than 65 years old across all income quintiles. Still, the bottom two quintiles receive more payments from Medicare than the top quintiles. This partly happens because people in low quintiles spend more on medical care in general as described earlier, and partly because private health insurance plays a more important role in financing health care of high-income people. 


\begin{tabular}{|c|c|c|c|c|c|c|c|c|c|}
\hline \multicolumn{10}{|c|}{ Ages 25+ } \\
\hline & \multicolumn{3}{|c|}{ Mean Income } & \multicolumn{3}{|c|}{ Mean Expenditure } & \multicolumn{3}{|c|}{ Mean Hospitals } \\
\hline & All & Men & Women & All & Men & Women & All & Men & Women \\
\hline All & 41,671 & 48,532 & 35,388 & 5,123 & 4,561 & 5,639 & 2,204 & 2,068 & 2,328 \\
\hline Bottom & 2,784 & 6,101 & 1,132 & 6,052 & 6,675 & 5,440 & 2,795 & 3,323 & 2,417 \\
\hline Fourth & 14,435 & 19,171 & 11,331 & 6,810 & 5,398 & 7,563 & 3,097 & 2,679 & 3,237 \\
\hline Third & 26,397 & 32,274 & 21,537 & 4,867 & 4,234 & 5,573 & 2,183 & 1,990 & 2,382 \\
\hline Second & 43,411 & 50,426 & 37,169 & 4,323 & 3,780 & 5,021 & 1,790 & 1,615 & 2,023 \\
\hline Top & 92,425 & 105,155 & 79,804 & 4,333 & 3,646 & 5,106 & 1,634 & 1,350 & 1,917 \\
\hline \multicolumn{10}{|c|}{ Ages 25-64 } \\
\hline & \multicolumn{3}{|c|}{ Mean Income } & \multicolumn{3}{|c|}{ Mean Expenditure } & \multicolumn{3}{|c|}{ Mean Hospitals } \\
\hline & All & Men & Women & All & Men & Women & All & Men & Women \\
\hline All & 44,243 & 51,109 & 37,665 & 4,055 & 3,470 & 4,616 & 1,717 & 1,537 & 1,889 \\
\hline Bottom & 2,426 & 6,461 & 577 & 5,190 & 5,379 & 4,790 & 2,388 & 2,644 & 2,129 \\
\hline Fourth & 15,600 & 21,196 & 11,341 & 4,657 & 3,352 & 5,613 & 2,089 & 1,637 & 2,355 \\
\hline Third & 28,716 & 34,579 & 23,496 & 3,585 & 2,996 & 4,008 & 1,621 & 1,413 & 1,715 \\
\hline Second & 46,072 & 52,956 & 39,758 & 3,537 & 3,072 & 4,291 & 1,405 & 1,312 & 1,730 \\
\hline Top & 96,023 & 108,336 & 83,396 & 3,810 & 3,105 & 4,619 & 1,435 & 1,096 & 1,726 \\
\hline \multicolumn{10}{|c|}{ Ages $65+$} \\
\hline & All & Men & Women & All & Men & Women & All & Men & Women \\
\hline All & 30,894 & 36,269 & 26,826 & 9,599 & 9,748 & 9,486 & 4,245 & 4,597 & 3,979 \\
\hline Bottom & 4,389 & 5,104 & 4,053 & 9,791 & 10,117 & 9,669 & 4,549 & 5,229 & 4,258 \\
\hline Fourth & 11,814 & 13,323 & 11,071 & 10,439 & 10,431 & 10,273 & 4,855 & 5,151 & 4,548 \\
\hline Third & 18,223 & 21,673 & 16,345 & 9,987 & 10,485 & 9,849 & 4,551 & 5,197 & 4,194 \\
\hline Second & 30,567 & 36,255 & 26,620 & 9,238 & 9,395 & 9,044 & 4,062 & 4,318 & 3,761 \\
\hline Top & 71,688 & 84,858 & 60,802 & 8,864 & 8,693 & 8,916 & 3,523 & 3,541 & 3,426 \\
\hline
\end{tabular}

Adjusted to 2014 dollars.

Table 10: Income and medical expenditures by income quintile and gender

\begin{tabular}{lccc}
\hline \multicolumn{5}{c}{ Total Expenditure } \\
\multicolumn{5}{c}{ All } & Men & Women \\
$25+$ & 0.72 & 0.55 & 0.94 \\
$25-64$ & 0.73 & 0.58 & 0.96 \\
$65+$ & 0.91 & 0.86 & 0.92 \\
Hospitals & & \\
\multicolumn{5}{c}{ All } & Men & Women \\
$25+$ & 0.58 & 0.41 & 0.79 \\
$25-64$ & 0.60 & 0.41 & 0.81 \\
$65+$ & 0.77 & 0.68 & 0.80 \\
\hline
\end{tabular}

Table 11: The ratio of the mean spending in the top income quintile to the bottom income quintile 


\begin{tabular}{lcccccc}
\hline \hline & All & Bottom & Fourth & Third & Second & Top \\
\hline Income & 41,671 & 2,784 & 14,435 & 26,397 & 43,411 & 92,425 \\
By Payor & & & & & & \\
Out of Pocket & 888 & 887 & 981 & 858 & 816 & 911 \\
Private Insurance & 2,183 & 1,881 & 1,669 & 1,979 & 2,392 & 2,674 \\
Government & 1,878 & 3,094 & 3,971 & 1,803 & 942 & 630 \\
$\quad$ Medicaid & 394 & 1,221 & 861 & 209 & 60 & 23 \\
$\quad$ Medicare & 1,286 & 1,565 & 2,769 & 1,399 & 753 & 504 \\
$\quad$ Other government & 198 & 308 & 341 & 195 & 128 & 103 \\
Expenditures & & & & & & \\
All & 5,123 & 6,052 & 6,810 & 4,867 & 4,323 & 4,333 \\
Hospitals & 2,204 & 2,795 & 3,095 & 2,184 & 1,790 & 1,634 \\
$\quad$ Inpatient & 1,713 & 2,304 & 2,580 & 1,708 & 1,311 & 1,140 \\
$\quad$ Outpatient & 491 & 491 & 516 & 476 & 479 & 494 \\
Office-based visits & 1,177 & 1,172 & 1,306 & 1,102 & 1,123 & 1,196 \\
Prescription drugs & 1,129 & 1,433 & 1,562 & 1,053 & 913 & 904 \\
Other & 613 & 652 & 845 & 528 & 496 & 600 \\
\hline
\end{tabular}

All variables sorted by income and adjusted to 2014 dollars

Table 12: Mean medical expenditure by income quintile and payor/expenditure type, for people older than 25 years old

The bottom panels of Tables 12 and 13 show how different categories of medical spending vary by income quintile. Spending on hospital care is almost two times higher among people at the bottom quintile comparing to those at the top quintile, and this difference comes from spending on inpatient care. Interestingly, for people older than 65 years old the gap between high- and low- income groups in inpatient hospital spending decreases, while outpatient spending increases monotonically with income for this age group. Spending on office-based visits varies little by income quintiles, while spending on prescription drugs is higher for low-income people. 


\begin{tabular}{lcccccc}
\hline \hline Ages 25-64 & All & Bottom & Fourth & Third & Second & Top \\
\hline Income & 44,243 & 2,426 & 15,600 & 28,716 & 46,072 & 96,023 \\
By Payor & & & & & & \\
Out of Pocket & 734 & 805 & 693 & 655 & 695 & 809 \\
Private Insurance & 2,315 & 2,014 & 1,857 & 2,173 & 2,465 & 2,750 \\
Government & 829 & 2,159 & 1,898 & 519 & 215 & 145 \\
$\quad$ Medicaid & 397 & 1,279 & 917 & 171 & 52 & 23 \\
$\quad$ Medicare & 281 & 596 & 737 & 218 & 77 & 37 \\
$\quad$ Other government & 151 & 284 & 244 & 131 & 87 & 85 \\
Expenditures & & & & & & \\
All & 4,055 & 5,190 & 4,657 & 3,585 & 3,537 & 3,810 \\
Hospitals & 1,717 & 2,388 & 2,088 & 1,621 & 1,405 & 1,435 \\
$\quad$ Inpatient & 1,280 & 1,926 & 1,686 & 1,207 & 980 & 965 \\
$\quad$ Outpatient & 437 & 462 & 402 & 414 & 425 & 470 \\
Office-based visits & 985 & 1,060 & 952 & 852 & 972 & 1,068 \\
Prescription drugs & 892 & 1,254 & 1,103 & 761 & 732 & 783 \\
Other & 462 & 488 & 512 & 351 & 429 & 524 \\
\hline Ages 65+ & & & & & & \\
& All & Bottom & Fourth & Third & Second & Top \\
\hline Income & 30,894 & 4,389 & 11,814 & 18,223 & 30,567 & 71,688 \\
By Payor & & & & & & \\
Out of Pocket & 1,534 & 1,237 & 1,417 & 1,554 & 1,599 & 1,715 \\
Private Insurance & 1,628 & 1,246 & 1,155 & 1,523 & 1,717 & 2,206 \\
Government & 6,274 & 7,212 & 7,759 & 6,730 & 5,752 & 4,724 \\
$\quad$ Medicaid & 380 & 970 & 750 & 376 & 108 & 22 \\
$\quad$ Medicare & 5,496 & 5,828 & 6,515 & 5,905 & 5,245 & 4,431 \\
$\quad$ Other government & 398 & 414 & 494 & 449 & 400 & 270 \\
Expenditures & & & & & & \\
All & 9,599 & 9,791 & 10,439 & 9,987 & 9,238 & 8,864 \\
Hospitals & 4,245 & 4,549 & 4,855 & 4,551 & 4,062 & 3,523 \\
$\quad$ Inpatient & 3,528 & 3,938 & 4,190 & 3,820 & 3,292 & 2,768 \\
$\quad$ Outpatient & 717 & 611 & 665 & 731 & 770 & 755 \\
Office-based visits & 1,984 & 1,659 & 1,817 & 1,983 & 2,035 & 2,248 \\
Prescription drugs & 2,122 & 2,224 & 2,272 & 2,210 & 2,037 & 1,952 \\
Other & 1,249 & 1,360 & 1,495 & 1,245 & 1,102 & 1,142 \\
\hline
\end{tabular}

All variables sorted by income and adjusted to 2014 dollars

Table 13: Mean Medical Expenditure by Income Quintile and Payor/Expenditure Type, for people older than 25 years old 


\subsection{The correlation of medical spending over time}

Table 14 reports the correlation of total and hospital medical spending over time, and Table A2 in the Appendix reports the correlation disaggregated by gender. Since MEPS has only 2-year panel dimension we can compute this correlation only between periods $t$ and $t+1$. The correlation is reported for the level of medical spending and for the logs. Since in the data many people have zero medical spending, we bottom-coded medical spending at $10 \%$ of the mean when taking log, i.e. people whose medical spending is below $10 \%$ of the mean were assigned the value of medical spending equal to $10 \%$ of the mean.

\begin{tabular}{|c|c|c|c|c|c|}
\hline \multicolumn{3}{|c|}{$\begin{array}{l}\text { A: Spending in Levels } \\
\text { Total }\end{array}$} & \multicolumn{3}{|c|}{ B: Spending in Logs } \\
\hline & $t$ & $t+1$ & & $t$ & $t+1$ \\
\hline All & 1.00 & 0.36 & All & 1.00 & 0.61 \\
\hline $25-$ & 1.00 & 0.29 & $25-$ & 1.00 & 0.40 \\
\hline $25-64$ & 1.00 & 0.35 & $25-64$ & 1.00 & 0.57 \\
\hline $65+$ & 1.00 & 0.32 & $65+$ & 1.00 & 0.58 \\
\hline \multicolumn{6}{|c|}{ Hospital } \\
\hline & $t$ & $t+1$ & & $t$ & $t+1$ \\
\hline All & 1.00 & 0.19 & All & 1.00 & 0.26 \\
\hline $25-$ & 1.00 & 0.09 & $25-$ & 1.00 & 0.16 \\
\hline $25-64$ & 1.00 & 0.20 & $25-64$ & 1.00 & 0.23 \\
\hline $65+$ & 1.00 & 0.15 & $65+$ & 1.00 & 0.26 \\
\hline
\end{tabular}

Table 14: Correlation of medical spending in year $t$ with spending in year $t+1$, by age and type of care

The correlation of medical spending in level is 0.36 and in logs it is 0.61 . When measured in logs the correlation for people younger than 25 years old is significantly lower as compared to other age groups. Hospital spending is less persistent than total medical spending: the correlation is 0.19 in levels and 0.26 in logs.

To better understand the dynamics of medical spending, Table 15 shows the transition matrix between quintiles of total medical spending distribution between time $t$ and $t+1$. Table A3 in the Appendix displays the same statistics for hospital spending. The persistence of medical spending varies by quintile of medical spending distribution: for people in the bottom and top quintiles, the probability to stay in the same quintile next period is around $54 \%$, whereas for the middle quintiles this probability varies from $31 \%$ to $36 \%$. In other words, individuals who spend little on health care as well as those who already experienced high medical shocks are more likely to continue this spending pattern for more than one period. This also shows that the overall persistence of medical spending measured as the correlation of total expenditures between two consecutive 


\begin{tabular}{r|ccccc}
\hline \hline \multicolumn{7}{c}{ Panel A: All ages } \\
Quintile & \multicolumn{5}{c}{ Next year } \\
Current Year & Bottom & Fourth & Third & Second & Top \\
\cline { 2 - 6 } Bottom & 53.9 & 24.9 & 11.9 & 5.7 & 3.6 \\
Fourth & 24.6 & 34.4 & 23.8 & 11.3 & 5.9 \\
Third & 11.9 & 23.4 & 31.0 & 22.5 & 11.2 \\
Second & 5.8 & 11.2 & 22.2 & 35.8 & 25.1 \\
Top & 3.8 & 6.1 & 11.2 & 24.7 & 54.2 \\
\hline
\end{tabular}

Panel B: Younger than 25

Quintile

Next year

\begin{tabular}{r|ccccc} 
Current Year & Bottom & Fourth & Third & Second & Top \\
\cline { 2 - 6 } Bottom & 47.0 & 23.6 & 13.9 & 9.0 & 6.5 \\
Fourth & 22.9 & 28.8 & 23.1 & 15.4 & 9.8 \\
Third & 14.1 & 22.4 & 25.7 & 22.6 & 15.2 \\
Second & 9.1 & 15.1 & 22.8 & 28.8 & 24.2 \\
Top & 6.8 & 10.2 & 14.5 & 24.2 & 44.2 \\
\hline
\end{tabular}

Panel C: Ages 25 to 64

Quintile Next year

\begin{tabular}{r|ccccc} 
Current Year & Bottom & Fourth & Third & Second & Top \\
\cline { 2 - 6 } Bottom & 56.5 & 23.9 & 10.5 & 5.4 & 3.7 \\
Fourth & 23.3 & 34.4 & 22.7 & 12.1 & 7.5 \\
Third & 10.4 & 22.7 & 30.9 & 22.9 & 13.0 \\
Second & 5.6 & 11.4 & 23.3 & 34.5 & 25.2 \\
Top & 4.2 & 7.6 & 12.6 & 25.0 & 50.6 \\
\hline
\end{tabular}

Panel D: Older than 65

\begin{tabular}{|c|c|c|c|c|c|}
\hline \multicolumn{2}{|c|}{ Quintile } & \multicolumn{3}{|c|}{ Next year } & \\
\hline Current Year & Bottom & Fourth & Third & Second & Top \\
\hline Bottom & 59.0 & 19.3 & 9.9 & 6.4 & 5.5 \\
\hline Fourth & 20.9 & 33.8 & 21.7 & 13.9 & 9.7 \\
\hline Third & 9.9 & 24.1 & 28.9 & 21.6 & 15.6 \\
\hline Second & 6.4 & 14.4 & 24.5 & 30.6 & 24.2 \\
\hline Top & 3.9 & 8.5 & 15.0 & 27.6 & 45.1 \\
\hline
\end{tabular}

Table 15: Transition matrices for total medical expenditure 
periods underestimates the risk of having a sequence of large medical shocks experienced by people at the top of medical spending distribution. High medical spending at the top is often a result of serious chronic diseases that require expensive treatments that last for more than one year. Note that relatively high persistence at the tails of the distribution happens at all ages, but with age persistence at the bottom becomes higher than that at the top.

Figure 1 plots the cumulative distribution functions for two variables: one-year medical spending and medical spending averaged over two years. The two lines are very close, suggesting that medical spending is persistent. ${ }^{8}$ Figure 2 shows that this is also the case for different age groups and for different types of medical care spending (hospital and non-hospital).

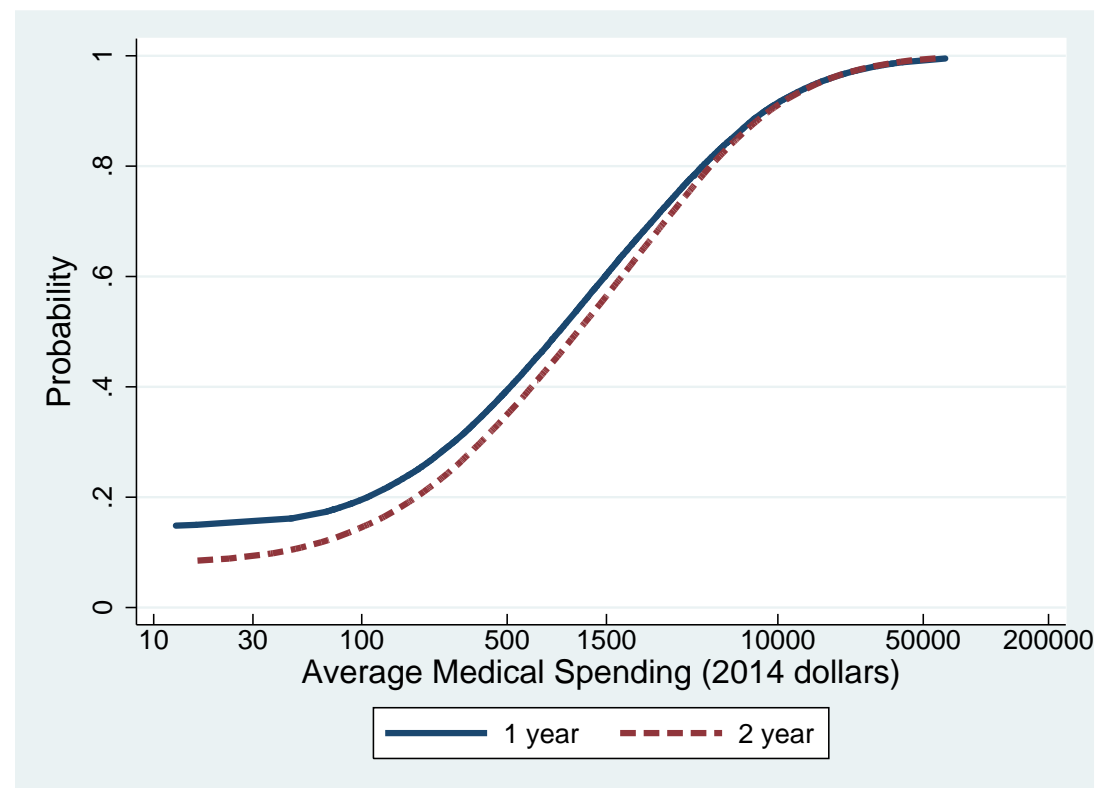

Figure 1: CDF of total medical expenditure, averaged over 1 and 2 years.

Table 16 reports the Gini coefficient and the share of the total medical spending by the top $1 \%$ and $10 \%$ of spenders. We document these statistics for yearly medical spending and for medical spending averaged over two years. Table 16 also shows how these statistics vary by age and the type of care (hospital and non-hospital). For the entire sample, the Gini coefficient is 0.76 for one- and 0.73 for two-year medical spending. ${ }^{9}$ Around $63 \%$ of the total spending are accounted for by the top $10 \%$ of spenders. The concentration decreases with age: for people aged between 25 and 64 years old the Gini coefficient is equal to 0.75 , whereas for people older than 65 years old it is 0.63 . Similarly,

\footnotetext{
${ }^{8}$ The more correlated is medical spending in $t$ and $t+1$, the closer together are cumulative distribution functions for the average medical spending over two-year period and for one-year medical spending. For example, if autocorrelation is one the two lines will be the same.

${ }^{9}$ The fact that Gini coefficient of medical spending averaged over two years is close to the Gini coefficient of one-year medical spending also implies high persistence.
} 
(a) By age
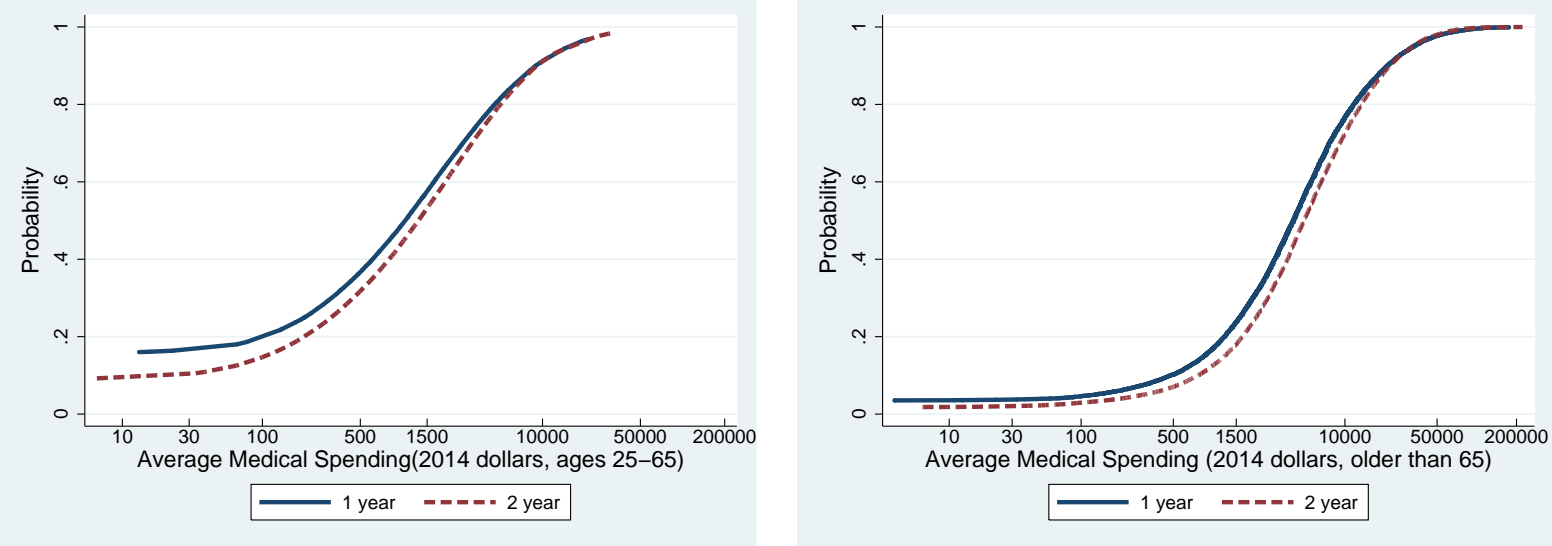

(b) By type of care
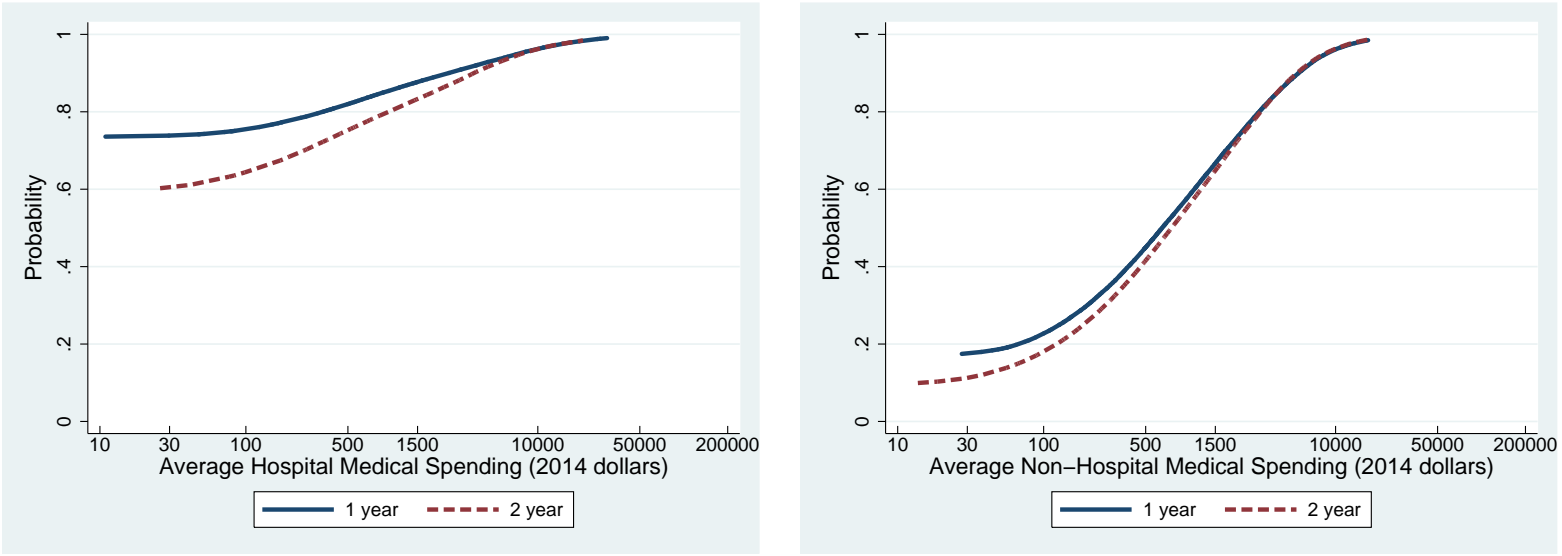

Figure 2: CDF of total medical expenditure, averaged over 1 and 2 years, by age and type of care.

the contribution of top $10 \%$ of spenders to the total is $61.4 \%$ for the younger group and $48.9 \%$ for the older. Hospital spending is more concentrated than total spending with the Gini coefficient equal to 0.93 .

\section{Average Medical Spending Over the Life Cycle}

Figure 3 plots the life-cycle profiles of the average medical spending disaggregated by type of expenditure (top panel) and payor (bottom panel). All categories of expenditure increase with age, and the growth rate noticeably accelerates from age 50 onward. The highest rate of growth is observed among inpatient hospital spending. The bottom panel shows a large change in the relative role of public and private insurance at age 65: before this age private insurance is the major source of financing medical spending, but afterwards Medicare is the main source. Spending financed by private insurance or Medicare increase with age over the segments of the life-cycle when they serve as major payors, while the spending of Medicaid remains relatively stable, primarily due to the absence of nursing home residents in our sample. 


\begin{tabular}{lcccccc}
\hline \hline & Over 1 year & \multicolumn{2}{c}{ By age } & \multicolumn{2}{c}{ By type of care } \\
& All & $25-64$ & $65+$ & Hosp & Non-hosp \\
\cline { 3 - 7 } Gini coefficient of medical spending & 0.76 & 0.75 & 0.63 & 0.93 & 0.73 \\
Percentage spent by top 1\% of spenders & $21.5 \%$ & $21.5 \%$ & $12.8 \%$ & $39.7 \%$ & $17.8 \%$ \\
Percentage spent by top 10\% of spenders & $62.8 \%$ & $61.4 \%$ & $48.9 \%$ & $92.3 \%$ & $56.2 \%$ \\
\hline & Over 2 years & \multicolumn{3}{c}{ By type of care } \\
& \multicolumn{2}{c}{ Bll } & $25-64$ & $65+$ & Hosp & Non-hosp \\
\cline { 3 - 7 } Gini coefficient of medical spending & 0.73 & 0.72 & 0.58 & 0.90 & 0.70 \\
Percentage spent by top 1\% of spenders & $18.2 \%$ & $18.6 \%$ & $9.6 \%$ & $31.3 \%$ & $15.9 \%$ \\
Percentage spent by top 10\% of spenders & $58.6 \%$ & $56.9 \%$ & $42.9 \%$ & $83.0 \%$ & $53.2 \%$ \\
\hline
\end{tabular}

Table 16: Measures of the concentration of medical spending by age and type of care

\section{Conclusion}

In this paper we document micro-level facts about medical spending in the US based on the Medical Expenditure Panel Survey dataset. Our main findings are as follows. For the entire population, around $44 \%$ of the total medical spending is paid by private insurance but there is a substantial difference in terms of financing medical care by age: for working age adults (25 to 65 years old) private insurance covers around $57 \%$ of the total medical spending, whereas for the elderly (older than 65 years old) the largest payor is the government which covers $65 \%$ of the total. Inpatient hospital care accounts for a third of the aggregate medical expenditures. Medical spending is highly concentrated: the top $5 \%$ of spenders account for more than half of the total expenditure. Even higher concentration is observed among hospital spending where the top $5 \%$ of spenders contribute around $80 \%$ to the total expenditure. The concentration in medical spending decreases with age: the Gini coefficient of the total medical spending is 0.75 for people aged between 25 and 64 years old and 0.63 for people older than 65 years old. We find that average medical spending of people in the bottom income quintile is higher than that of people in the top income quintile for all age groups. In terms of persistence of medical spending, we find that the correlation of medical expenditure in two consecutive years is 0.36 . When persistence is measured by quintile of medical spending distribution, medical spending of people in the bottom and top quintiles has higher persistence relative to other groups.

\section{References}

[1] Aizcorbe, A., Liebman, E., Pack, S., Cutler, D., Chernew,M., Rosen, A., 2012. "Measuring health care costs of individuals with employer-sponsored health insurance in 


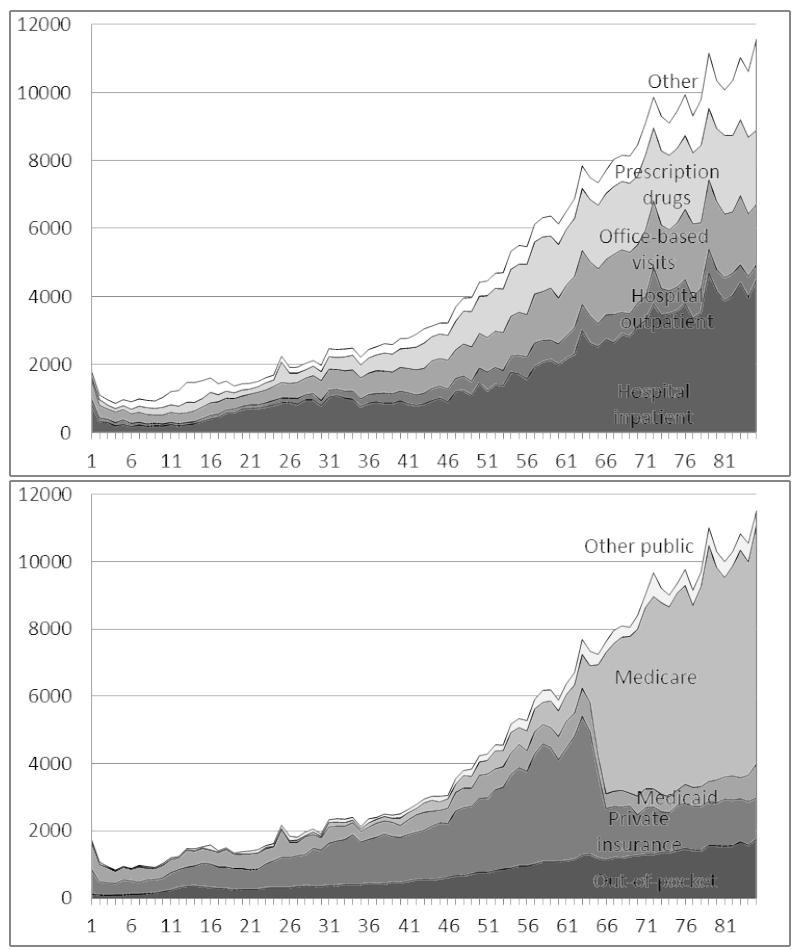

Figure 3: Average total medical expenditures, by expenditure (top panel) and payor type (bottom panel)

the U.S.: A comparison of survey and claims data." Statistical Journal of the IAOS, vol. 28 , no. 1,2

Banthin, J., Selden, T., 2006. "Income Measurement in the Medical Expenditure Panel Survey". Agency for Healthcare Research and Quality Working Paper No. 06005.

[2] Bernard, D., Cowan, C., Selden, T., Cai, L., Catlin, A., Heffler, S., 2012. "Reconciling Medical Expenditure Estimates from the MEPS and NHEA, 2007". Medicare and Medicaid Research Review: Volume 2, Number 4

[3] Calonico, S., Hirth, R., Gibson, T., Levy, H., Smith, J., Das, A., 2015. "Long-term Health Spending Persistence among the Privately Insured: Exploring Dynamic Panel Estimation Approaches,' Mimeo.

[4] Crystal, S, Johnson, R., Harman, J., Sambamoorthi, U., and Kumar, R. 2000. "Outof-Pocket Health Care Costs among Older Americans,' Journal of Gerontology: Social Sciences 55(1), S5I-S62.

[5] Czajka, j., and Denmead, G., 2008. "Income Data for Policy Analysis: A Comparative Assesment of Eight Surveys". Report, Mathematica Policy Research.

[6] De Nardi, M., French, E., Jones, J., McCauley, J., 2015. "Medical Spending of the U.S. Elderly". Mimeo.

[7] Evans, R., Humpherys, J., 2015 "U.S. Healthcare Spending Trends from Aggregated Monthly Claims Data,' Mimeo 
[8] Fahle, S., McGarry, K., Skinner, J., 2015. "Out-of-Pocket Medical Expenditures in the United States: Evidence from the Health and Retirement Study,' Mimeo.

[9] Goldman, D., and Zissimopoulos, J., 2003. "High Out-of-Pocket Health Care Spending by the Elderly,' Health Affairs 22(3), pp 194-202.

[10] Hurd, M., and Rohwedder, S., 2009. "The Level and Risk of Out-of-Pocket Health Care Spending,' Michigan Retirement Research Center Working Paper 218.

[11] Jung, J., Tran, C., 2014. "Medical consumption over the life-cycle". Empirical Economics, Volume 47, Issue 3, pp 927-957

[12] Kaiser Family Foundtion, 2013. "Employer Health Benefits. Annual Survey". Available at https://kaiserfamilyfoundation.files.wordpress.com/2013/08/8465-employerhealth-benefits-20131.pdf

[13] Selden, T., Levit, K., Cohen, J., Zuvekas, S., Moeller, J., McKusick, D., and Arnett, R. 2001. "Reconciling Medical Expenditure Estimates from the MEPS and NHA, 1996." Health Care Financing Review, 23(1), pp 161-178

[14] Singh, M., Banthin, J., Selden, T., Cowan, C., Keehan, S., 2006. "Reconciling Medical Expenditure Estimates from the MEPS and NHEA". Health Care Financing Review. Volume 28 (1).

[15] Smith, J, Medalia, C., 2013. Health Insurance Coverage in the United States: 2013. US Census Bureau. Available at http://www.census.gov/library/publications/2014/demo/p60-250.html

[16] Yabroff, R, Warren, J, Banthin, J., Schrag, D, Mariotto, A, Lawrence, W., Meekins, A., Topor, M., Brown, M., 2009. "Comparison of Approaches for Estimating Prevalence Costs of Care for Cancer Patients: What Is the Impact of Data Source?" Medical Care Vol. 47, No. 7

\section{Appendix}

Supplementary Tables 


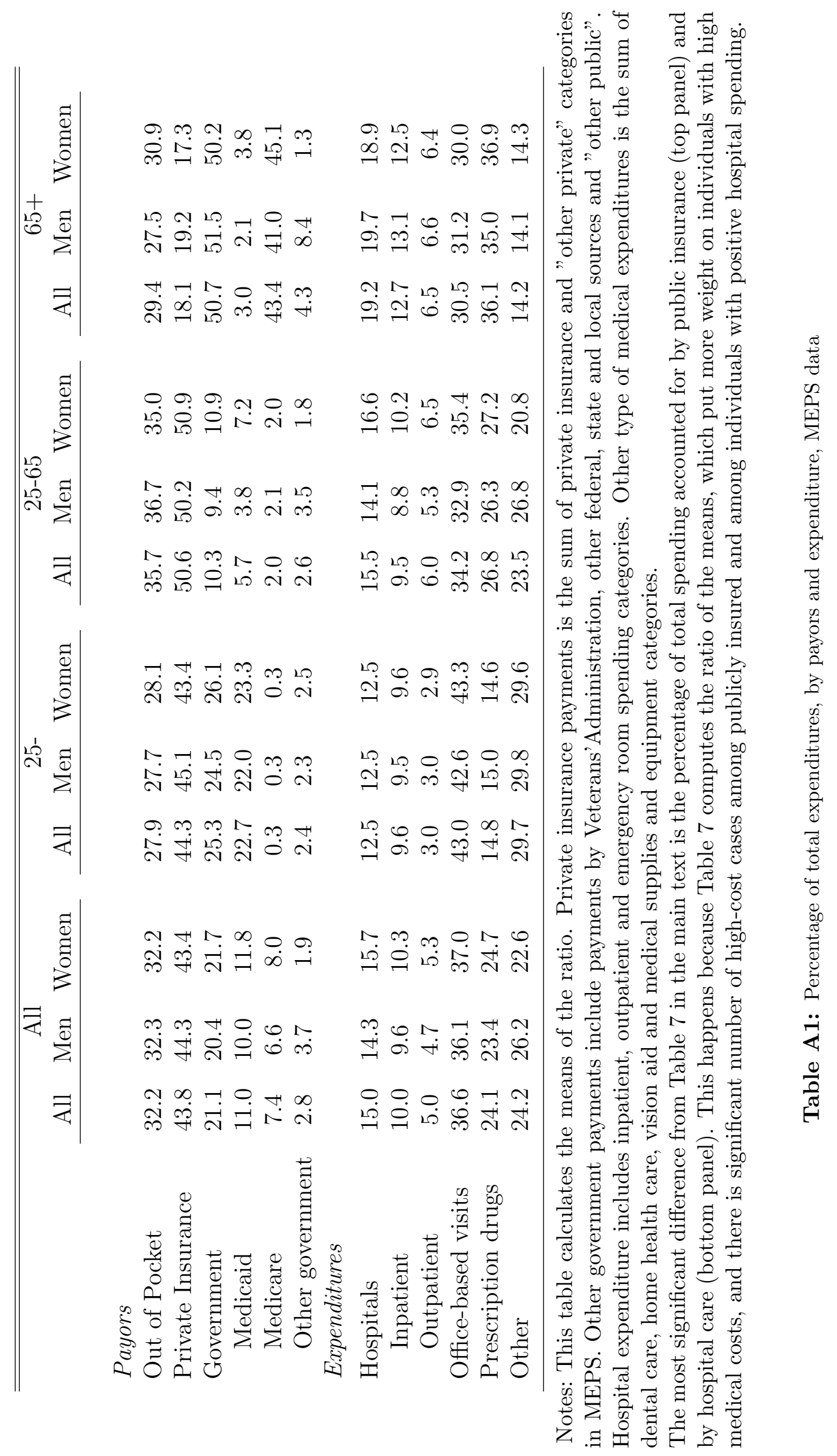




\begin{tabular}{|c|c|c|c|c|c|}
\hline \multicolumn{3}{|c|}{$\begin{array}{l}\text { A: Spending in Levels } \\
\text { Total }\end{array}$} & \multicolumn{3}{|c|}{ B: Spending in Logs } \\
\hline & $t$ & $t+1$ & & $t$ & $t+1$ \\
\hline All & 1.00 & 0.36 & All & 1.00 & 0.61 \\
\hline Men & 1.00 & 0.34 & Men & 1.00 & 0.61 \\
\hline Women & 1.00 & 0.40 & Women & 1.00 & 0.59 \\
\hline & $t$ & $t+1$ & & $t$ & $t+1$ \\
\hline All & 1.00 & 0.19 & All & 1.00 & 0.26 \\
\hline Men & 1.00 & 0.21 & Men & 1.00 & 0.27 \\
\hline Women & 1.00 & 0.16 & Women & 1.00 & 0.24 \\
\hline
\end{tabular}

Table A2: Correlation of medical spending in year $t$ with spending in year $t+1$, by gender and type of care 


\begin{tabular}{r|cccc}
\hline \hline \multicolumn{5}{c}{ Panel A: All ages } \\
Quintile & \multicolumn{3}{c}{ Next year } & \\
Current Year & Bottom-Third & Second & Top & - \\
\cline { 2 - 5 } Bottom-Third & 80.7 & 4.9 & 14.5 & \\
Second & 57.9 & 13.6 & 28.5 \\
Top & 53.6 & 8.8 & 37.6 \\
- & & & \\
- & & & \\
\hline
\end{tabular}

Panel B: Younger than 25

\begin{tabular}{r|ccc}
\multicolumn{2}{c}{ Quintile } & \multicolumn{3}{c}{ Next year } \\
Current Year & Bottom-Second & Top & - \\
\cline { 2 - 4 } Bottom-Second & 85.4 & 14.6 & - \\
Top & 68.2 & 31.8 \\
- & & \\
- & & \\
- & & \\
\hline
\end{tabular}

Panel C: Ages 25 to 64

\begin{tabular}{|c|c|c|c|c|c|}
\hline \multicolumn{2}{|c|}{ Quintile } & \multicolumn{4}{|c|}{ Next year } \\
\hline Current Year & Bottom-Third & Second & Top & - & - \\
\hline Bottom-Third & 80.3 & 5.0 & 14.7 & & \\
\hline Second & 56.6 & 14.0 & 29.5 & & \\
\hline Top & 55.1 & 8.8 & 36.2 & & \\
\hline & & & & & \\
\hline
\end{tabular}

Panel D: Older than 65

\begin{tabular}{r|cccc}
\multicolumn{2}{c}{ Quintile } & \multicolumn{3}{c}{ Next year } \\
Current Year & Bottom-Fourth & Third & Second & Top - \\
\cline { 2 - 5 } Bottom-Fourth & 64.2 & 6.0 & 15.3 & 14.4 \\
Third & 43.2 & 13.7 & 25.6 & 17.6 \\
Second & 39.7 & 11.4 & 27.2 & 21.7 \\
Top & 34.8 & 6.8 & 24.2 & 34.2 \\
- & & & & \\
\hline
\end{tabular}

Notes: We combine several bottom quintiles into one since the average spending in these quintiles is zero.

Table A3: Transition matrices for hospital medical expenditure 